\title{
Digitized indigenous knowledge collections: Impact on cultural knowledge transmission, social connections, and cultural identity
}

\author{
Chern Li Liew $^{1}$ | Jamie Yeates ${ }^{2} \quad$ Spencer Charles Lilley ${ }^{3}$
}

${ }^{1}$ School of Information Management, Victoria University of Wellington, Wellington, New Zealand

${ }^{2}$ Te Kawa a Māui (School of Māori Studies), Victoria University of Wellington, Wellington, New Zealand

${ }^{3}$ Te Uru Maraurau, Massey University, Palmerston North, New Zealand

\section{Correspondence}

Chern Li Liew, School of Information Management, Victoria University of

Wellington, PO Box 600, Wellington 6140, New Zealand.

Email: chernli.liew@vuw.ac.nz

\section{Funding information}

Victoria University of Wellington, Grant/ Award Number: Victoria University of Wellington Foundation - Dig

\begin{abstract}
This research examines the impact of digitized and digital indigenous knowledge collections (D-IKC) on cultural knowledge transmission, social connections, and cultural identity through semi-structured interviews with 8 users of D-IKC in New Zealand. The participants acknowledged that D-IKC brought about many benefits, including the surfacing of otherwise hidden or inaccessible cultural heritage. Concerns around digital access, digital competency, and responsiveness to cultural values need to be thoughtfully addressed nevertheless. Use of D-IKC had impact not only at an individual level but also at a social-community level. We highlight several traditional cultural values related to D-IKC use that are not embodied in existing value-impact frameworks. This research also found that the intersection and interactions among individual needs, cultural expectations, and norms and affordances around the digital information environments concerned were nuanced and multifaceted. These facets must be incorporated into the stewardship of knowledge collections. We also observed "digital knowledge sharing in the wild"-knowledge transmission that transpired and in some cases led to creation of knowledge resources that materialized outside the bounds of the originating repositories and institutions. Further studies into such self-organized knowledge transmission/sharing phenomena can lead to valuable insights to inform and shape the curation and design of D-IKC.
\end{abstract}

\section{1 | BACKGROUND}

The UNESCO Declaration Concerning the Intentional Destruction of Cultural Heritage (UNESCO) emphasizes the linkages between cultural heritage and identity of individuals, communities, and social cohesion (UNESCO, 2003). Appropriate stewardship of cultural heritage has the capacity to recover and empower cultural identity (Harrison, 2010). Memory institutions (MIs) preserve and make accessible cultural knowledge and documentary heritage to disseminate knowledge and to create positive social impact (Moss, 2017). Such cultural heritage projects have proclaimed new forms of cultural transmission and cultural citizenship. Scholarly literature on usage of digital heritage collections and their impact on individuals and communities remain scarce however.

A previous research (Crookston et al., 2016) found evidence that usage of digitized Māori language (te reo Māori) collections led to the development of knowledge sharing relationships (whanaungatanga) among users and their communities. There was indication that the value gained from the usage was beyond an individual level and that the digitization of indigenous knowledge 
collections led to positive impact at a familial-community level. This warrants further investigation. This is the motivation for this research.

This research addresses a gap in scholarly literature about the impact of digitized and digital indigenous knowledge collections (hereafter, D-IKC), specifically around potential impact on cultural knowledge transmission, social connections, and cultural identity. This research focuses on indigenous knowledge collections in te reo Māori accessible through MIs in NZ. Evidence of knowledge sharing and transmission prompted by D-IKC, as well as people's perception and expectations of the development and provision of D-IKC, was examined through semi-structured interviews with eight participants. Our participants informed us that digitization of D-IKC brought about many benefits, including the surfacing of otherwise hidden or inaccessible cultural heritage. Concerns around digital access, digital competency, and responsiveness to cultural values need to be thoughtfully addressed nevertheless. The participants also revealed that apart from the barriers associated with the availability of technology (hardware, software, and Internet connections), there was an additional layer of complexity related to the ethics of accessing and sharing digital materials that belonged to members of another $i w i$ (tribes). They emphasized the importance that whakapapa (genealogy) played in decision making. This is discussed in more depth in section 4.4. We purport here that this is a distinguishing characteristic of how Māori and other Indigenous peoples engage with D-IKC.

This research provides insights that would guide the development and management of D-IKC and other cultural knowledge collections, particularly those aimed at promoting self-determination, cultural empowerment, and social cohesion. The study also informs the broader discourses around cultural heritage's materiality through digital technologies.

\section{2 | RELATED WORKS}

\section{1 | Memory institutions and digital indigenous knowledge}

Memory institutions (MIs) - galleries, libraries, archives, and museums-“transmit experience and creativity across the borders of time and space, language and custom, people and individuality" (Byrne, 2015, p. 260). The memory sector's base principles of free and equal access to information has, however, been at odds with indigenous paradigms, where communities may have their own emic hierarchies of knowledge access, needing a more guarded approach to the transmission of certain cultural knowledge (Buchtmann, 2000; Burns et al., 2009; Capponi, 2010; Hall, 2016; Marsh et al., 2015; Nakata et al., 2007). Marett et al. (2006) highlight the importance of a mutual acknowledgement of ownership and guardianship in a national-level project of recording and preserving cultural knowledge. Kral (2011) looks at the use of digital media by Australian aboriginal youth, noting its parallel ability to engage younger generations with traditional Indigenous knowledge while allowing practice of information sovereignty over digitized versions of their knowledge.

Conventionally, MIs hold the power to decide what indigenous knowledge is of value to preserve and hence, what is or is not to be maintained in their collections. Christen (2015) states that the mismanagement of digital cultural materials by the memory sector could potentially continue the trajectory of colonization and argues that a closer collaboration between information professionals and indigenous communities to understand their requirements is much needed to avoid or mitigate this. Scholars have called for a scrutiny of institutional policies and roles associated with indigenous knowledge management (Lindh \& Haider, 2010; Roy \& Trace, 2018).

A review by Tiakiwai and Tiakiwai (2010) regarding e-learning platforms in kaupapa Māori (principles and values) education suggest that more research is needed to examine the impact of digital collections on users. The ability to present digital collections in multimedia formats gives a flexibility that may not be possible with physical materials. In the case of ethnographic knowledge, digitization enables the accessibility of richer sociocultural and historical contextual information. Concerns around trust in source authenticity and accuracy (Whaanga et al., 2015) have been raised nevertheless. Developments aim at addressing such concerns include projects that move towards hosting collections on indigenous-friendly platforms where information can be organized and transmitted according to vernacular community principles and values (Hall, 2017; Hall \& Love, 2012; Ka'ai-Mahuta, 2012).

Another common theme in the literature is that cultural property (taonga) can be developed with community input, incorporating respect and conformity to traditional values (Horwood, 2017; Ka'ai-Mahuta, 2012; Keegan \& Gregory, 2007; Whaanga et al., 2015). Custodianship (kaitiakitanga) is often discussed. The discourse around digitization typically frames it as a means for facilitating preservation and an avenue to improve the accessibility of cultural knowledge. Also noted is the archival profession's power over vulnerable communities whose heritage they are meant to protect (Davidson, 2015). Emphasized is the place whānau (extended families), hapu (subtribes), and iwi (tribes) should hold in discussing collection 
management requirements, and the importance of collaborative and reciprocal relations between institutions and stakeholders (Hall, 2017; Keegan \& Gregory, 2007; Lilley, 2016; Whaanga et al., 2015).

While never explicitly discussed, a few other studies, apart from Crookston et al. (2016), illustrate the impact DIKC may have on social relationships. Mato's (2009) exploration of a D-IKC as a pedagogical resource noted that contact with other students, respected elders, (kaumātua) and instructors increased engagement with resources. In another study of a student-built Māori digital atlas collections (Mercier et al., 2013), relationships developed both within and outside of the class were highlighted as key factors affecting the level and quality of engagement with the digital atlas. Engagement with the digital atlas prompted relationships development among the students and their instructors, and between students and community groups through the contacts students made with local iwi bodies for clarifications of toponyms.

\section{2 | Assessing impact}

Meyer (2011) highlighted a scarcity of scholarly research on assessing impact of digital cultural heritage collections. Those that have made attempts reiterate the difficulty in quantifying impact. Impact in this context is typically discussed as economic impact, social impact, and educational impact. Identifying and articulating social impact is considered the most challenging. Generally, a need for mixed-method approaches are emphasized (Kanuka \& Kelland, 2008; Lyons, 2012; Marsh et al., 2015; Poll, 2003). Punzalan et al. (2017) and Kanuka and Kelland (2008) argue for the importance of evidence that center users experience and perception in the assessment.

Also highlighted in the literature are the inherent difficulties in the impact assessment of collections that hold cultural significance to indigenous communities (Crookston et al., 2016; Marsh et al., 2015; Punzalan et al., 2017). Often connected with extant indigenous communities, culturally sensitive collections hold a unique place in institutions and are rarely candidates for impact assessment.

Reuse is considered a key impact indicator but as Chapman et al. (2016) note, "One of the most prominent gaps in the literature involves isolating and understanding patterns of reuse" (p. 5). Few attempts have been made within the memory sector to track the reuse of digital objects through web analytics and reverse image lookup (Mannheimer et al., 2016; Reilly \& Thompson, 2017) and via user assessment (Kelly et al., 2018; Reilly \& Thompson, 2017; Woolcott et al., 2018). Nevertheless, few institutions collect data on reuse of digital objects. Woolcott et al.
(2018) and Thompson et al. (2017) suggested that an absence of widely accepted methodology and a lack of best practice references could be the reasons.

\subsection{1 | Values and impact frameworks}

Several frameworks were identified and considered in view of their potential in lending a set of lenses to focus the data analysis of this investigation.

Tanner (2012) introduced the balanced value impact (BVI) model:

- Utility value: being able to use a digital resource.

- Education value: the ability to learn and gain knowledge.

- Community value: the experience of being part of a community engaging with a digital resource.

- Existence/prestige value: knowing that a digital resource exists and is prized by people, whether it is used personally or not.

- Inheritance/legacy value: the ability to pass forward or receive digital resources, including the satisfaction of knowing that descendants or other members of their communities will be able to benefit from a resource.

Tanner contextualizes these values through four strategic perspectives (Tanner, 2020, pp. 89-92). Social impacts consider how users and the wider society have been positively affected by a resource. Economic impacts refers to the financial implications of a resource to the institution, stakeholders, or society. Innovation impacts consider how a digital resource enables innovation, and the social and economic benefits resulting from that innovation. Operational impacts examines how the institution has benefitted in its own internal processes by the innovation. The BVI model acknowledges the interrelation of the various impacts. It contextualizes impact not just for the institution, but also on the lives of users of the resources.

In a study of Māori language vitality, Higgins and Rewi (2014) drew out seven values:

- Intrinsic value: Māori language as an integral part of Māori identity.

- Educational value: value of the language in contributing to academic achievement.

- Social value: social standing and respect gained as a result of Māori language abilities.

- Cultural value: fulfillment of cultural demands.

- Intellectual value: enrichment of Māori worldview through the language.

- Spiritual value: connection to ancestral heritage. 
- Monetary value: the economic outcomes, associated with other values.

Attitudes towards these values are foregrounded: "These seven values regulate the attitudes that people have towards the Māori language. We propose that as a consequence of one's relative orientation towards or away from these values, one's perception, attitude and use of the Māori language is simultaneously orientated in the same direction" (Higgins \& Rewi, 2014, pp. 9-10). These values allow us to conceptualize potential impact within a schema that is "by Māori for Māori."

Sheth et al.'s (1991) theory of consumption values highlighted:

- Functional value: the utility, performance, and upfront benefits of a product.

- Conditional value: the context-dependent value of products and services.

- Social value: using a product associated with a certain group.

- Emotional value: a product's ability to evoke an emotional response.

- Epistemic value: the value of a product based on its ability to arouse curiosity and produce new experiences and/or knowledge (Sheth et al., 1991, pp. 160-162).

This theory has its origin in a business research context but its value components have been applied to the study of library collections and services (Misilei \& Liew, 2018 , p. 220). The theory has been found useful in its ability to contextualize user choices and preferences, and a resource's potential impact: Why was one resource used/reused over another? What are the value drivers that encourage engagement with a resource? As such, it complements other value frameworks.

\section{3 | Social connections and social cohesion}

Identity is acknowledged for its inter-relationality. People's identities "emerge" from the social relations around them (Mutibwa, 2016). Even though no studies have directly addressed the potential impact of collections on social cohesion, there are acknowledgement of the potential of D-IKC as catalyst for fostering social relationships and cultural identity among users, between users and communities (Crookston et al., 2016; Hannele \& Multisilta, 2015; Mercier et al., 2013).

Buchtmann (2000) conducted a longitudinal study of the Australian Northern Territory Warlpiri adoption of modern communication technology. The Warlpiri community was involved in the codevelopment of the digital platforms which they used to establish and strengthen links with neighboring aboriginal communities as well as for furthering claims of Indigenous selfdetermination. Another example of the impact of digital platforms on social relationships was documented by Ashmore (2013). In this case, websites acted as extensions of existing relationships and "enable[d] a hybrid space, in which interactions within the virtual space enhance and accentuate the appreciation of...social relationships based there [Shetland]" (p. 271).

Spoonley et al. (2005) discuss how statements around social cohesion in institutional policies acknowledge imbalances among differing ethnic groups. While focusing on immigrant experiences in NZ, the central themes of civic participation and community interaction with institutional processes highlight the potential effects the memory sector can have on social cohesion. Durie (2009) explores the connection between educational institutions and socially cohesive environments for Māori communities. Accordingly, the visibility of Māori-centric components such as wānanga (a publicly owned tertiary institution that provides education in a Māori cultural context), Māori departments in universities and Ngā Pae o te Māramatanga (NZ's Māori Centre of Research Excellence) contribute to an increase of trust and Māori participation in societies. Durie (2009) and Spoonley et al. (2005) highlight the importance of community trust in institutional practices and their impact on social participation.

\section{3 | RESEARCH DESIGN}

There remains a considerable gap in knowledge about the usage and impact of D-IKC on individuals and communities. There is also a lack of knowledge on how to assess and contextualize such resulting impact. In this research, we examine D-IKC use and their significance on cultural knowledge transmission and cultural identity. The insights gained inform decisions around curation, and the design and shaping of D-IKC and other documentary heritage repositories aimed at promoting community engagement, cultural identity, and social cohesion.

A phenomenological design was applied. According to Leedy and Ormrod (2015), a phenomenological study "attempts to understand people's perceptions and perspectives relative to a particular situation" (p. 273). Phenomenological methods have been found to be effective at bringing to the fore individual reflective experiences (Smith et al., 2009). Phenomenological approaches enabled us to elicit and surface deep issues experienced and perceived by our participants. The approaches also helped us in our attempt to expose systemic and 
normative assumptions about indigenous communities experience with D-IKC. Approval to conduct the research was granted by Victoria University of Wellington Human Ethics Committee. A copy of the human ethics application can be obtained from the corresponding author.

\section{1 | Participants}

It is common for a phenomenology study to work with a small sample. It involves studying a specific group and is not aimed at making claims about the general population (Leedy \& Ormrod, 2015; Smith et al., 2009). A purposeful sampling was applied in this research to allow for an in depth, narrative-based investigation of participants' experiences, perceptions, and attitudes concerning the significance and impact of D-IKC.

Participants were recruited through the personal and professional networks of the researchers. Following several rounds of invitations for participation, five students and three academics were recruited. Six interviews were conducted between June and October 2019, and following a disruption due to the COVID-19 pandemic, two more interviews during July and August 2020. During the gap, the first six interviews were transcribed and open coding was conducted. Table 1 outlines the profile of the participants, including the collections they have used and the purpose of their use/reuse of the D-IKC. Details for these collections are included as Data S1, Supporting Information.

\section{2 | Approaches to data collection and analysis}

Participants were offered the option of being interviewed in English and/or te reo Māori. They were also given the option of having a whānau (family member or support person) accompanying them during the interview. The interviews ranged from 40 to $75 \mathrm{~min}$. The interviews were guided by a set of questions, centered on the nature of D-IKC access and use, sharing/repurposing of resources/knowledge, reflection on impact on cultural knowledge transmission, social connections, and cultural identity, and expectations around the development and delivery of D-IKC and the associated services. During recruitment, potential participants were provided a copy of the interview guide that outlined the focus of the intended interview (included as Data S2).

Face-to-face interviews were conducted because of the importance of face-to-face communication (kanohi ki te kanohi) in Māori worldview (te ao Māori). This was especially important once it was established that all participants were of Māori descent. At the start of the interviews, a moment was taken for relationship building (whakawhanaungatanga). This is an integral process in interviewing Māori (Gillies et al., 2007; Lacey et al., 2011). The purpose of whakawhanaungatanga was to create a space for reciprocal sharing about the participant's and interviewer's lives and provide the interviewee an opportunity to voice any concerns or queries about the research and the nature of the questions. These approaches enabled the elicitation of rich narratives. Stewart (2019) states, "Narrative research approaches respect the radical teaching power of stories, in line with Indigenous sensibilities" (p. 78). In the context of this research, narrative research allows for deep exploration of participants' lifeworldhow it recursively shapes and is shaped by D-IKC.

All interviews were audio-recorded and manually transcribed. The second-named author translated the Māori excerpts. Participants were given the opportunity to review the transcripts of their interviews. This study uses interpretive phenomenological analysis (Smith et al., 2009) that places value on each individual participants' experience and views while drawing out characteristics that are shared across participants. The qualitative, inductive data analysis undertaken involved several rounds of questioning, reflecting, and interpreting, with concepts drawn from the literature review and the valueimpact frameworks in mind. The data were also analyzed with a kaupapa Māori (Māori principles and values) lens so that cultural issues associated with the participants actions were surfaced. The analysis was exploratory in nature, to provide insights on a social phenomenon that has not yet been studied extensively.

Collaboration among the three researchers was an important feature in this study, bringing a combination of insider and outsider perspectives. The second-named author is of Māori descent and is familiar with a number of the D-IKC both as a scholar and a tutor. This insider perspective brought multiple significances, including facilitating recruitment of the interviewees, building rapport, establishing rational authority and the ability to understand te reo Māori, its history and implicit knowledge inherent in the participants' accounts of their experience and views with regard to the D-IKC. The firstnamed author, who conceived the idea for this research, designed the study, led the analysis and the writing of this manuscript, was unfamiliar with the community of participants at the commencement of the data collection and was hence in a position to provide the necessary critical distance and critical insight for the data analysis (Dwyer \& Buckle, 2009). The third-named author was not involved in the conduct of the research but was invited to contribute to this manuscript, bringing his expertise in kaupapa Māori, thus contributing as an outsider in the context of the research, but with an insider knowledge of the topical area. 
TA B LE 1 Profile of participants and outline of collection use

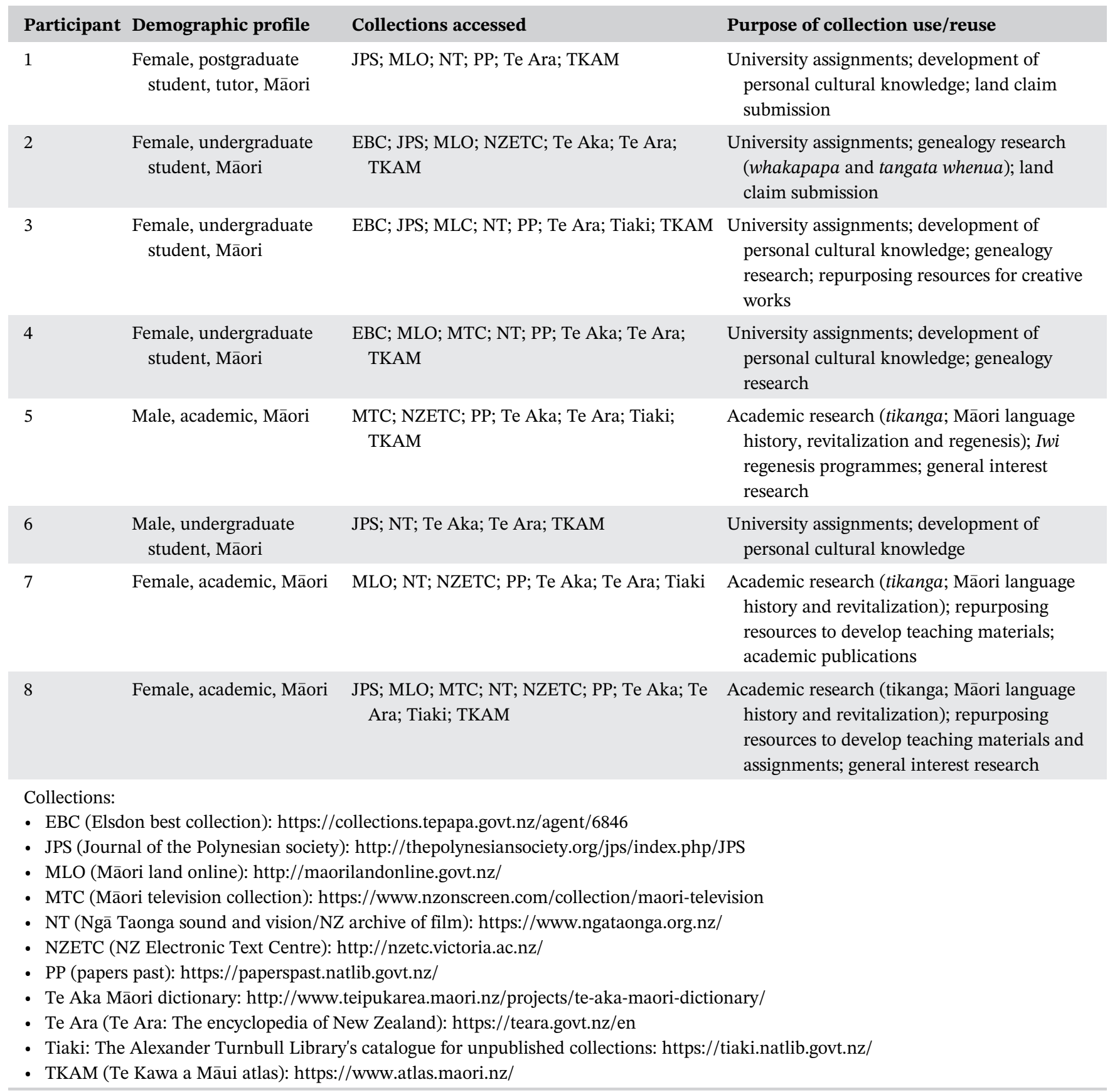

\section{4 | FINDINGS}

\section{1 | Use of collections}

Given the participants were students and academics, it was unsurprising that most of them used the D-IKC for assignment purposes and for teaching and academic research, respectively. Also noted were the use of collections for personal interest and development, such as researching whakapapa and whenua (land) information either for themselves or for others, language revitalization projects or for creative works. From a cultural perspective, usage of these resources demonstrated a significant link between individuals and the networks they interact with. Core values here include whakawhanaungatanga and reciprocal knowledge exchange (tauutuututanga).

Having online access to not only textual documents but audiovisual resources such as oral history recordings was highlighted. 
It's really great that some of the oral and visual treasures have also been digitized and made available digitally. I find great value in them and I have also referred some of my students to these collections. I even had one student telling me how she was mesmerized listening to a kaumatua recounting a kōrero (conversation/discussion/ stories).

\section{(Participant 8)}

A couple of participants recounted the significance of emotional and spiritual connections (wairuatanga) gained from the audio aspect:

The resources I accessed were those of ancestral past. I like to listen to the whaikōrero (formal speech-making) of the past. One of my university courses was on karanga (ritual chant of welcome) and whaikōrero. While I was doing the research, I sat and listened to them.

(Participant 2; translated)

It's better to listen to the audio resources because you can feel the wairua (spirit/soul) and the flow of the language. That's better than just reading the words.

(Participant 1; translated)

\subsection{Accessibility and discoverability}

Although some of the collections are available for physical access at the institutions concerned, all participants reported preference for online access. All agreed that having these collections digitized and made available through digital platforms increased the visibility of the resources that might otherwise remained undiscovered, and the potential for wider access and convenient use. Purposeful learning-teaching $(A k o)$ about these resources provides a sense of cultural satisfaction and recognition that the knowledge can make contributions to others through whanaungatanga, tauutuututanga, and whakapapa.

The fact that it's documented is great, but that it's online is even better because there are some resources that are documented that aren't even accessible to us or if they are, they are very hard to find. I don't know how much I can stress the fact that having an online platform where you can go and access te reo Māori collections is very helpful.

(Participant 1)

With technology changing quite a bit and how back in the day everything having to do with Māori was quite oral, you necessarily had to be there and hear what they were saying to understand it, but now that it's all been documented and moved to an online platform where it can be stored and accessed at all time, that's the part that makes these collections most useful.

(Participant 4)

It's good to see these sorts of resources on the Internet because that's the world we live in these days. Thinking of the youth of today, they very much inhabit this technological and digital world. It relates better to them.

(Participant 5; translated)

Three commented, however, that the websites through which they accessed the collections seemed not to have been designed for access via mobile devices. One of the comments:

The interface is really awkward to use. The layout is not amenable to scrolling, and the search and browse features are probably OK for use on a PC or laptop but very difficult to navigate through a smaller mobile phone screen.

\section{(Participant 7)}

Lack of awareness of the collections was mentioned by all interviewees as another barrier to access. Three students commented that they only became aware of the collections through instructors' recommendations.

It's hard to find these resources. I hadn't heard about these resources until my university study. They're not spoken of in my community. That's probably an issue.

(Participant 4; translated)

I am concerned and yeah, somewhat disappointed. They (referring to MIs) invested in the digitization but seem to have forgotten to 
inform the people about these resources. They are really valuable resources but what is the point if they are hidden and not used? Then the management say, oh, these resources are not used, and we should stop funding the digitization of the collections. I believe this is a serious problem. The people and communities can benefit from these collections hugely but they are not aware that they can be accessed online.

\section{(Participant 8)}

Yet another barrier to the use of these collections mentioned by the participants was the lack of digital competence to search and navigate these collections through the websites and digital platforms, and inadequate digital access among some members of communities.

I don't pass them on to my family or extended family because they don't have the digital skills to access and use them.

(Participant 4; translated)

There are all these talks about digital skills and digital inclusion in the cultural sector and by the government but what are they doing for the community, especially our elders and those without adequate digital skills to use these collections? Some of them would benefit from these information but they don't have the knowledge and easy access to these digital collections. Digital literacy is still an issue even among some of the young I would say, and yes, some people don't have easy access to the Internet or even to a computer.

\section{(Participant 7)}

Certain collections were also highlighted as being difficult to access due to the lack of appropriate functionalities such as lack of support to search in Māori language in Papers Past and no obvious options to browse collections in Māori terms in Papers Past and NZETC.

\section{3 | Collections features and functionalities}

Several interviewees noted that some resources in the collections were digital scans and did not allow for text search while some appeared to have issues with OCR or inaccurate transcriptions.
A useful aspect is the search bar. If I prepare for an essay, I'll go to Papers Past, type in a word, a keyword and the results appear. But, sometimes the transcription of the text is either wrong or illegible.

(Participant 6; translated)

For Māori Land Online, the fact that you could go in there, type any name and it would come up with all the information pertaining to that name, that was very useful because it cut out all the work of having to go to your nan, or your kaumātua, and asked about whakapapa. Whereas if you just went on to the online platform, it saves the hassle.

\section{(Participant 4)}

Te Ara lists pretty much every topic and the fact that it was bilingual is great. If I wasn't able to understand a word in Māori, I'd just go to the English translation and then it would help me get back to the Māori side of it. That was a really helpful tool.

(Participant 3)

One participant indicated that they were wary of any te reo material that was not produced by a speaker from their tribe, resulting in errors and inaccuracies:

That's not my language. It's not accurately translated. I hold to my own dialect.

(Participant 4)

This demonstrates the significance of correct use of te reo Māori in the transmission of knowledge where errors/inaccuracies can alter the meaning of words and result in less positive use and impact. Such inaccuracies may deter engagement with D-IKC. It also has an influence on the restoration of mana (prestige) to the language and the knowledge contained within it.

Others discuss how the language itself could be a barrier for access and use, and suggested that thoughtful integration of bilingualism into the resources should be considered.

Some of these resources should have subtitles or have translations for the many people who don't know te reo Māori or specific dialect. 
(Participant 5; translated)(Participant 5; translated)

\subsection{Sharing of knowledge resources}

The effects on knowledge transmission where kaumātua as traditional knowledge keepers and at times, gatekeepers are bypassed in the context of digital collections is of interest. All interviewees reported having shared and transferred knowledge resources they encountered in the digitized collections at some point. All the student participants reported sharing via mainly their Facebook networks, including with their fellow students and marae (traditional Māori meeting house) group. Sharing occurred via the companion Messenger app and through "posting" to a Group. Sharing also occurred via word-ofmouth, emails and via USB devices and Bluetooth transfers. This was the case for the academics as well. The value of all these exchanges is expressed through the cultural values of ako, whanaungatanga, tauutuututanga, whakapapa, and whakamana.

Sometimes I hear something good on Ngā Taonga, I share it so that my family and friends can listen too. I've also sent my university mates resources that I thought would be useful for their assessments. It's generally much easier to share via Facebook. No need to go through gatekeepers.

(Participant 3; translated)

For one assignment, it was about the birthing practices of Māori and I did a comparison between traditional versus modern views. The traditional view of Māori birthing practices, the traditional sources were really hard to track down via Google. I went through Te Ara, then I found some in the Elsdon Best Collection and I used Facebook and I found people who had knowledge of traditional birthing practices. They were able to lead me to more sources. I probably wouldn't have found those sources if I didn't have that platform and those people.

\section{(Participant 4)}

Interviewees commented that materials were more likely to be shared if they are related to the participant's tribal affiliations, and sharing of materials occurred within genealogical networks. Information to support land claims and genealogy research were the primary reason for sharing with whānau. Accessing material specific to other iwi was not framed positively in general. One participant noted that if they were to access other iwi material, they would feel more comfortable if it were iwi with closer whakapapa ties to them. This points to the prominence of genealogical links and self-identity, the spirituality of cultural knowledge, and the recognition that the restrictive nature of certain traditional knowledge are a form of integrityprotection.

Sharing take place both in person and online. The fact that we didn't know about this information before made it more important that once we obtained this information that we would pass it on to those who we thought also wouldn't know. Knowing that there were some places we didn't even know we whakapapa back to, that importance right there of not knowing. You want to know your tūrangawaewae (a sense of identity), you want to know where you come from, you want to know where you can go stand on the marae.

\section{(Participant 1)}

Sharing was often framed with reference to positive learning and social outcomes. Educational resources were shared with classmates, and material relevant to whannau were sent along familial networks. The cultural values of whanaungatanga and tauutuututanga were evident with a link to purposeful learning-teaching of traditional knowledge.

It is not knowledge if it is not transmitted and shared. It is liberating to be able to bring information and knowledge back to whānau through what digital technologies have made possible.

(Participant 7)

When we [students] prepared for tests and for certain assessments, it was very helpful in that sense that I as well as other students would share that information that we had obtained that could help with those tests and assessments because, for one, it helped us all pass but we were also able to share all our knowledge and get a deeper understanding of our cultural identity together.

(Participant 4) 
I pass on these sorts of resources to my family because most haven't even graduated high school so they might not have come across these knowledge through word-of-mouth or through their kaumātua. It's a good tactic, so that they know the history of te ao Māori that they haven't come across. It's easy for them to listen to the oral histories. It also brings everyone closer having this shared heritage and knowledge.

(Participant 3; translated)

A few interviewees expressed tentativeness in sharing however, when they perceived that the information they encountered might not be appropriate to share such as those considered to be tapu (sacred), including certain whakapapa knowledge, especially if the material was outside of one's tribal roots. The need for sensitive handling of sacred knowledge and the uniqueness of different mātauranga a $\overline{-}$-iwi (tribal knowledge systems) must be considered and reflected in the development and access management of D-IKC.

\section{5 | Reuse and repurposing of resources}

Interviewees provided insights into the various contexts for reuse and repurposing of collection materials, including for dialectal revitalization and the regenesis of their tribal historical corpus. One interviewee spoke about the reintroduction of cultural knowledge back into the tribal oral corpus-how she and fellow students recreated and performed a traditional mōteatea (song-poetry) from their tribes.

When these words were returned to the iwi, it was a relief. It was important for our cultural identity.

\section{(Participant 3; translated)}

This interviewee also recounted that following the knowledge sharing, a collaborative decision was made by the tribal body and the interviewee to reoralise some of the textual materials. A traditional waiata (song) which had not been sung in a century was redeveloped with a new tune and this was taught to younger members of the tribe for a kapa haka (traditional Māori dancing and chanting) performance. A tribal pepeha (epithet) was also recreated by the iwi from historical materials encountered in D-IKC.

Another revitalization project mentioned was on developing a corpus of iwi-specific lexemes, a collection of words found in their dialectal area. As their dialect is currently not spoken by any native speakers and physical archive collections were inconveniently distant, D-IKC were utilized to find ancestral speakers and writers of the dialect. These demonstrated the application of whakamana (legitimacy, empowerment/status restoration) to te reo and mätauranga $\bar{a}$-iwi through the use of these resources. However, the participant noted that this was limited to only materials that had been digitized, which was not the case for a large portion of te reo Māori archives.

Another participant recounted the revitalization of a traditional game form.

I found an article on JPS about kōruru, which is similar to knucklebones. The students had to read the article about the game. The article explained the rules of the game, its cultural significance, quotes from people living in that time. To my knowledge, the article was dated 1870 . So it's pretty old. That was cool to the students.

\section{(Participant 1; translated)}

This interviewee mentioned that students who learnt the game in turn, taught others outside of the classroom about it-thus facilitating cultural knowledge transmission beyond the classroom. Use of these resources also led to significant ako and the restoration of mana (spiritual life force/social standing/prestige) to traditional knowledge.

Some collection materials were used as a source of inspiration for creative writing. One participant discussed the reuse of older textual material and how this prompted an emotional connection to their ancestor and the impact on cultural identity, providing a link between whakapapa and $a k o$, and a renewed status to te reo Māori.

When I do creative writing, I weave their words with mine. For me, this type of activity links me with my tūpuna (grandparent or ancestor). It strengthens my poetic and literary skills. It strengthens my cultural identity. It also calms me.

\section{(Participant 3; translated)}

Another interviewee talked about the stylistic influence on her own writing.

When I write a mihi (formal greeting), I use the words and ideas sourced from the farewells and other submissions on Papers Past.

\section{(Participant 1; translated)}

She emphasized however that she only reused material from her tribes, as far as she could determine their 
origins, again highlighting the value of in-built features in D-IKC to facilitate this.

Another interviewee noted a whānau member's reuse of audiovisual material from Ngā Taonga in produced filmwork after being made aware of the D-IKC by the interviewee, integrating old photographs and samples of ethnographic film into new forms.

Reuse of material sourced from D-IKC for use in bureaucratic contexts reported by our participants focused on land claims. Two participants were involved in land issues with local governmental bodies and businesses, and reused materials from D-IKC as evidence of past claims and ancestry connections. Both participants reported that despite both scenarios ending in failed claims, educational booklets were produced from the research material that explained the cultural significance of the land, its history, and the whakapapa links that bound the whannau to the area.

Barriers to reuse mentioned by the interviewees relate to the uncertainty about ancestry and tribal links to some resources, and lack of digital competency in repurposing materials. One other major reason mentioned was the lack of affordances to facilitate reuse. In the case of textual materials, poor quality OCR and inaccuracies in transcriptions were mentioned. For audio resources, a couple of interviewees mentioned the lack of accurate timetracking and poor audio quality as reasons that discouraged reuse.

A few interviewees reported a culturally bound reason for not reusing material, citing a need for not only confidence of genealogical connection, but a certain level of social standing to be needed in order to reuse material, especially if it were of a sensitive nature. One interviewee recounted an incidence where iwi members outside of their own whakapapa network were contacted for permission to reuse a resource in their assessment. This was to keep both the interviewee's and the iwi's mana intact.

\section{6 | Perceived benefits: Cultural and social connections}

All participants noted that benefits gained from the use of D-IKC encompass not only linguistic and cultural knowledge but also information about their cultural identity-associated with whānau/hapü/iwi, and the ability to share these knowledge with their communities, thereby fostering social connections. One interviewee mentioned the gain of deeper understanding of whakapapa connections and how that facilitated connections to previously unknown whenua:

I've used Māori Land Online for personal reasons apart from for university work, just to research pretty much all the land I whakapapa back to and that was quite enlightening because there are actually some places I didn't know I whakapapa back to until I had a look through it with my mother. I shared this with my whānau. In fact, it was actually through other whānau members that I was able to get hold of this information.

\section{(Participant 4)}

Spiritual connection (wairuatanga) to ancestries gained through engagement with older materials is a common mention.

It's a glimpse into the past. I experience a spiritual connection with the histories.

(Participant 1; translated)

Reading those diaries or journals-you really feel the wairua of those in the past. It's a binding rope. These sorts of resources possess a lot of wairua.

(Participant 2; translated)

Another benefit of utilizing D-IKC was how they acted as exemplars for digital archiving and preservation. Two participants divulged their hapu's plans to set up their digital archives for distant, diaspora relatives.

These provide excellent examples and inspiration. We are finding ways to digitize some of our own kōrero like these.

(Participant 5; translated)

\section{7 | Development and provision of D-IKC}

A few interviewees believed that MIs could benefit from more Māori specialists with a deep understanding of tikanga for the development and stewardship of D-IKC. The other rationale offered was that Māori practitioners have deeper connection to the resources, as such, more culturally adept in navigating the tikanga around them. These interviewees believed that institutions should also encourage non-Māori staff to develop their te reo Māori and understanding of tikanga so that they can contribute to culturally appropriate stewardship of D-IKC.

Certain institutional decisions and practices were highlighted as problematic. All interviewees noted having come across resources and information in D-IKC that 
should not be openly accessible to all. They argued that access/use restrictions should had been put in place for these resources. This was referred to as an example where Western conceptions clashed with te ao Māori and the need for increased awareness of the sacredness of traditional knowledge.

They're tapu. Let's not besmirch that. The institutions should have been more aware and responsible about this. This shows either their lack of awareness or lack of respect.

(Participant 6; translated)

We need to look after these. Not everyone should look at them. There are some real confidential, tapu stuff in there. People can raweke (distort/manipulate) it.

\section{(Participant 2)}

The institutions should ask and consult with the whānau before putting up these materials.

\section{(Participant 4)}

Comments from participants indicated that a degree of expertise in traditional knowledge (tohungatanga) was required to ensure appropriate knowledge stewardship and for the value of D-IKC to be truly realized.

There is apparent ignorance in the management of the resources. There appears to be no understanding of tikanga Māori. I have a feeling that they have not consulted with the right people and iwi when deciding what to digitize, how to categorize and organize the resources, what to make available freely through these digital collections and what access restrictions are needed. It is a real concern. This can lead to mistrust in institutions as the so-called guardians of mātauranga Māori.

(Participant 8)

\section{5 | DISCUSSION}

The summary in Table B1 outlines the key findings of this study as they relate to the value impact frameworks (Higgins \& Rewi, 2014; Sheth et al., 1991; Tanner, 2012, 2020). We also highlight the traditional cultural values emerged from our findings.

\section{1 | Cultural knowledge transmission and social connections}

All participants indicated that knowledge sharing occurred mostly along familial networks. This is unsurprising, as there is a noted preference for engaging with material emerging from their own tribal contexts. Participants are more likely to share material that is central to their genealogy. Proximity/centrality appears to be a characteristic of the relationship systems formed around cultural knowledge sharing. The closer to the center of a system, the more likely material is to be engaged with and shared, and the more likely that individuals will have material shared with them.

The use of digital platforms to "extend" relationships beyond immediate localities has been discussed (Ashmore, 2013; Buchtmann, 2000). With the shareability of D-IKC along previously established relationship networks, the resources aid in extending and fostering these networks-an impact of whakawhanaungatanga. The new social connections established around transmission and sharing of D-IKC were mediated largely via social media. Whanaungatanga as a social system in the D-IKC context appears to be dynamic. There is relational variation as to who belongs within the centrality and periphery of the relationship system. Who is on the periphery or centrality depends on the resources concerned. While new whānau may not be within the centrality of the participant's usual social system for instance, in regards to the D-IKC that connects the two networks, they become central to the whanaungatanga.

\section{2 | Use/reuse, cultural knowledge transmission, and cultural identity}

Within the context of a culture that leans heavily on orality, the conceptual boundary of "reuse" and "transmission" becomes blurred. All participants noted their use of social media, mainly Facebook for sharing D-IKC. Participants commented on the ubiquity of social media platforms. They also shared that their key relationships, their whānau, and friends were already established within their social media networks, hence greatly facilitating the sharing and transmitting of knowledge resources. While early contact lead to the adoption of Western standards by Māori and a decrease in oral transmission, there now appears to be a shift to bringing what is textual back into the spoken (oral). Adoption of digital technology has opened another avenue up, with social media platforms facilitating straightforward sharing and transmission of textual and audiovisual (i.e., oral/aural) resources. 
As the majority of our participants were university students, it came as no surprise that reuse took place in the context of preparing for coursework. Heritage revitalization was another context for reuse. Many iwi are in the process of linguistic and cultural regenesis, utilizing archival collections for researching and resurfacing tribal written artifacts, and remnants of reclaimed anthropology and ethnography. Creative projects were another context for reuse. Re-envisioning of traditional waiata and kapa haka, and incorporation of historical texts in creative writing were examples.

The ability to share and reuse information from DIKC has been described as "liberating," engendering a connection with ancestral figures that inhabited their world, and in doing so broadens their understandings of their past, their self- and cultural identity. Revitalization projects draw upon that underpinning philosophy of ancestral engagement, aiming for cultural wellbeing via shared heritage.

\section{3 | Areas noted for improvement}

Information professionals see themselves as disseminators of knowledge. They desire to educate as many people as possible about the collections under their care. This is viewed as an intersection between institutional practices and traditional customs. According to Māori cultural practice, it is not always appropriate for certain knowledge to be freely available to anyone who seeks it or even to those who may come across it incidentally, as can easily occur in the digital sphere.

Concerns were raised with regard to the management and care of D-IKC based on Anglo-American/Western frameworks. Almost all participants voiced the importance of Māori specialists to manage D-IKC on the premise that they would do so in a culturally appropriate manner as kaitiaki (custodians). This is deemed important as traditional knowledge have spirituality, life-force, social standing and some are sacred. The NZ memory sector recognizes that Māori are stewards of their cultural properties and experts on their own heritage and that $i w i$, $h a p \bar{u}$, and whānau have intellectual property rights when it comes to what is done with their cultural heritage, including the digitization and dissemination of these knowledge (Francis \& Liew, 2009). This points to the significance of embedding traditional cultural values in the stewardship of traditional knowledge collections.

Durie (2009) notes that the visibility and integration of Māori-centric forms and models within institutions contribute to an increase of Māori participation and trust. Communicating and demonstrating cultural competences with D-IKC stewardship, with evidence of a tikanga approach could have a positive impact on engagement with D-IKC in the care of MIs.

Noting the shared discomfort among our interviewees in engaging with traditional knowledge outside of their own iwi, one approach worthy of consideration is to allow flexibility in cultural heritage stewardship. Currently, the majority of digital and analog indigenous collections are still centralized and located within a few government-level institutions (such as the national library and national archive). Supporting the development of tribal-based and regional archives where traditional cultural resources are digitized, organized, and managed as appropriate to local requirements of custodianship could strengthen engagement with the knowledge collections.

Issues around digital access and digital competency also need to be addressed. The variation in individuals' access to and prowess at using digital technology must be addressed in the design and development of digital platforms supporting access to and use of cultural knowledge collections. If not addressed appropriately, this could lead to divisions rather than cohesion within communities (Choi \& Song, 2020; de Jong et al., 2019). It is also important to avoid setting up a binary division between those with access and those without, and making assumption that simply enabling digital access will address the issues. Digital access and digital competencies are nuanced and exist on a spectrum due to the interactions between cultural, social, political, technological, and economical differences.

\section{6 | CONCLUSIONS}

Information is power, increasingly bestowed through technology to enrich peoples' lives (Makri, 2020, p. 1411). Connecting knowledge resources with communities is the raison d'être for MIs. This research has shown how access and use of D-IKC have significant impact on cultural identity (both individual and collective) and social connections. The lack of collection visibility needs to be addressed however. It is insufficient for institutions to simply invest in digitizing and developing traditional knowledge collections. MIs also need to invest in outreach programmes and raising awareness of the resources. These can be partnered with programmes aimed at improving digital access and developing digital competency. This research has found that human agency can be an empowering influence and can be established as trusted digital entry points to digital collections. For instance, digitally competent (usually younger) members in communities acting as "coaches" and "ambassadors" to raise awareness of digital collections that can benefit their 
familial-social networks, imparting digital literacy, expediting the adoption of technology and contributing to accelerating learning to help their communities to benefit from D-IKC. Follow-up studies should investigate these further.

Overall, our participants concluded that the digitization of D-IKC have brought about many benefits. D-IKC have enabled the surfacing of otherwise hidden or inaccessible cultural heritage: the "liberating effect" mentioned by one interviewee-bringing information closer to individuals and their social and familial networks through what has been afforded by digital technologies, allowing them to engage, re-engage, revitalize, innovate, and transmit cultural knowledge and contributing to strengthening of individual and collective cultural identity. Concerns around adverse effects on the spirituality of cultural materials are generally perceived to be outweighed by ease of access and ease of sharing knowledge resources. Issues around cultural sensitivity concerning sacred knowledge and genealogical materials need to be carefully handled nevertheless. Appropriate consultation and partnerships with indigenous authorities is crucial in this respect.

The "multiplier effect" was mentioned-that is, sharing prompted by an obligation to share knowledge, associated with whanaungatanga to strengthen relationships and sense of connectedness, and this sharing had been afforded and made easy via digital technologies (e.g., through Facebook Messengers Groups and emails, via USB devices and Bluetooth transfers). These kinds of sharing and passing on of knowledge leads to an interesting phenomenon which in this context, might be termed "digital knowledge sharing in the wild"-knowledge sharing that took place and in some cases, led to creation of knowledge resources that materialized outside the bounds of the originating repositories and institutions. This has been motivated, as this research shows, by technological and social-cultural factors. Further studies into such 'in the wild' user behaviour (Chamberlain \& Crabtree, 2020), the self-organised knowledge transmission and sharing phenomena, and the associated social fabric (Avital et al., 2021) can lead to valuable insights to inform and shape the development and design of D-IKC.

Developing and sustaining the relevance and value of D-IKC requires relationship management among three parties-institutions that manage and provide access to the resources, those whose stories/records are held within the collections (as authors/creators or subjects of the records), and those who use the knowledge resources. Reciprocity is not only an important concept for Māori, it is also something that institutions can benefit from. MIs should incorporate the concepts of manaakitanga (care, mutual respect) and tikanga into all aspects of their institutional decision making, processes, and practices.

Our research findings have emphasized a number of traditional cultural values (highlighted in Table B1) related to the use of D-IKC that have not been embodied in previous value-impact frameworks. These need further scrutiny. In the Māori worldview, there is a notion of "tuakana-teina" that stemmed from the relationship concept between siblings or cousins where the older (tuakana) of the two acts as an advisor to the younger (teina). The learning can go both ways nevertheless. The roles can be reversed, depending on who has what knowledge. This is a useful conceptualization for information professionals who are involved in the digitization and management of indigenous knowledge in their care. They should be willing to defer to the expertise of tangata whenua ("people of the land") and the customary values of the communities concerned. In a follow-up study, we will investigate a D-IKC stewardship framework that prioritizes sociocultural inclusiveness and responsiveness to indigenous needs based on this notion as well as that of the connection between kaitiaki (cultural and spiritual knowledge custodians) and kaipupuri (knowledge/ records stewards).

Studies of value-impact of digitized and digital cultural knowledge need to take into consideration the dynamics of familial-social relationships and their influence on the use experience of D-IKC. This research has shown that the intersection and interactions among individual needs (including knowledge pursuit and cultural identity), social norms and cultural conditions (customs, protocols, collective cultural identity), and the norms and affordances around the digital information environments concerned are nuanced and multifaceted. These various facets and the intersections and interactions also call for further investigations.

\section{ACKNOWLEDGEMENTS}

We would like to thank our interview participants for their interest in this research as well as for their openness in sharing and for their trust. Ngā mihi nui. We thank the two anonymous reviewers and the Review Editor for their close reading of our submission and for offering a number of valuable suggestions. Chern $\mathrm{Li}$ would also like to extend an appreciation to the Editorin-Chief, Professor Steven Sawyer for his always prompt, courteous and constructive responses to inquiries. An appreciation too, to Max Baddeley for reading a manuscript of this paper and for his considered comments. This research was funded by the Victoria University of Wellington Foundation - Digital Innovation Fund - Spearheading Digital Futures Grant 3643-219804 awarded to Chern Li Liew. 


\section{ORCID}

Chern Li Liew (D) https://orcid.org/0000-0002-4293-4800

\section{REFERENCES}

Ashmore, R. (2013). "Far isn't far": Shetland on the internet. Visual Studies, 28(3), 271-282.

Avital, M., Jensen, T. B., \& Dyrby, S. (2021). The social fabric framework: Steps to eliciting the social making of organisations in the digital age. European Journal of Information Systems, https://doi.org/10.1080/0960085X.2021.1907236.

Buchtmann, L. (2000). Digital songlines: The use of modern communication technology by an aboriginal community in remote Australia. Prometheus, 18(1), 59-74.

Burns, K., Doyle, A., Joseph, G., \& Krebs, A. (2009). Indigenous librarianship. In M. J. Bates \& M. N. Maack (Eds.), Encyclopedia of library and information sciences (3rd ed., pp. 2330-2346). Taylor \& Francis.

Byrne, A. (2015). Institutional memory and memory institutions. Australian Library Journal, 64(4), 259-269.

Capponi, D. L. (2010). Perceptions of digital libraries with indigenous knowledge: An exploratory study. Retrieved from http://trace. tennessee.edu/utk_gradthes/610/

Chamberlain, A., \& Crabtree, A. (2020). Research "in the wild". In A. Chamberlain \& A. Crabtree (Eds.), Into the wild: Beyond the design research lab. Studies in applied philosophy, epistemology and rational ethics (Vol. 48). Springer. https://doi.org/10.1007/ 978-3-030-18020-1_1

Chapman, J., DeRidder, J., Hurst, M., Elizabeth, K., Kyrillidou, M., Muglia, C., O'Gara, G., Stein, A., Thompson, S., \& Trent, R. (2016). Surveying the landscape: Use and usability assessment of digital libraries. Retrieved from https://osf.io/9nbqg/.

Choi, J.-C., \& Song, C. (2020). Factors explaining why some citizens engage in E-participation, while others do not. Government Information Quarterly, 37(4). https://doi.org/10.1016/j.giq.2020. 101524.

Christen, K. (2015). Tribal archives, traditional knowledge, and local contexts: Why the "s" matters. Journal of Western Archives, 6(1), 3

Crookston, M., Oliver, G., Tikau, A., Diamond, P., Liew, C. L., \& Douglas, S.-L. (2016). Kōrero Kitea: Ngā hua o te whakamamatitanga/The impacts of digitized te reo collections. Retrieved from https://interparestrust.org/assets/public/ dissemination/Korerokiteareport_final.pdf

Davidson, J. (2015). The colonial continuum: Archives, access and power. Archifacts, 2015(April), 17-24.

de Jong, M. D. T., Neulen, S., \& Jansma, S. R. (2019). Citizens' intentions to participate in governmental co-creation initiatives: Comparing three co-creation configurations. Government Information Quarterly, 36(3), 490-500.

Durie, M. (2009). Towards social cohesion: The indigenisation of higher education in New Zealand. Presented at Vice Chancellors Forum, Kuala Lumpur.

Dwyer, S. C., \& Buckle, J. L. (2009). The space between: On being an insider-outsider in qualitative research. International Journal of Qualitative Methods, 8, 54-63.

Francis, K., \& Liew, C. L. (2009). Policy and protocols for digitized indigenous knowledge in cultural heritage organisations in Australia and New Zealand. In Proceedings of 2009 ASIS\&T annual meeting: Thriving on diversity-Information opportunities in a pluralistic world, Vancouver, Canada, 6-11 November (Vol. 46, pp. 37-54). ASIS\&T.

Gillies, A., Tinirau, R., \& Mako, N. (2007). WhakawhanaungatangaExtending the networking concept. He Pukenga Korero, 8(2), 29-37.

Hall, C. (2016). Māori archives and records. Archifacts, 2016 (December), 43-48.

Hall, C. (2017). Mukurtu for mātauranga Māori: A case study in indigenous archiving for reo and tikanga revitalisation. In $\mathrm{H}$. Whaanga, T. T. Keegan, \& M. Apperley (Eds.), He whare hangarau māori language, culture \& technology (pp. 189-199). Hamilton, NZ: University of Waikato and Faculty of Māori and Indigenous Studies.

Hall, C., \& Love, H. (2012). Ka puta, ka ora: Digital archiving and the revitalisation of Taranaki reo. Archifacts, 2012(April), 25-34.

Hannele, N., \& Multisilta, J. (2015). Digital storytelling promoting twenty-first century skills and student engagement. Technology, Pedagogy and Education, 20, 1-18.

Harrison, R. (2010). Heritage as social action. In S. West (Ed.), Understanding heritage in practice (pp. 240-276). Manchester University Press.

Higgins, R., \& Rewi, P. (2014). Right-shifting: Reorientation towards normalisation. In R. Higgins, P. Rewi, \& V. OlsenReeder (Eds.), The value of the Māori language Te Hua o te Reo Māori (pp. 7-32). NZ: Huia Publishers.

Horwood, M. (2017). Going digital in the GLAM sector: ICT innovations \& collaborations for taonga Māori. In H. Whaanga, T. T. Keegan, \& M. Apperley (Eds.), He whare hangarau Māori language, culture \& technology (pp. 165-177). Hamilton, New Zealand: University of Waikato: Faculty of Māori and Indigenous Studies.

Ka'ai-Mahuta, R. (2012). The use of digital technology in the preservation of Māori song. Te Kaharoa, 5(1). https://www. tekaharoa.com/index.php/tekaharoa/article/view/98.

Kanuka, H., \& Kelland, J. (2008). Has E-learning delivered on its promises? Expert opinion on the impact of E-learning in higher education. Canadian Journal of Higher Education, 38(1), 45-65.

Keegan, T., \& Gregory, A. (2007). Indigenous language usage in a digital library: He Hautoa Kia Ora Tonu Ai. The University of Waikato.

Kelly, E. J., Muglia, C., O'Gara, G., Stein, A., Thompson, S., \& Woolcott, L. (2018). Measuring reuse of digital objects: Preliminary findings from the IMLS-funded project. In Proceedings of the 18th ACM/IEEE on joint conference on digital libraries (pp. 351-352). ACM/IEEE.

Kral, I. (2011). Youth media as cultural practice: Remote indigenous youth speaking out loud. Australian Aboriginal Studies, $1,4$.

Lacey, C., Huria, T., Beckert, L., Gilles, M., \& Pitama, S. (2011). The Hui process: A framework to enhance the doctor-patient relationship with Māori. NZ Medical Journal, 124(1347), 72-78.

Leedy, P. D., \& Ormrod, J. E. (2015). Practical research and design (11th ed.). Pearson Education.

Lilley, S. (2016). Ko Aotearoa Tenei: Indigenous cultural and intellectual property rights in Aotearoa New Zealand. In C. Callison, L. Roy, \& G. LeCheminant (Eds.), Indigenous notions of ownership and libraries, archives and museums (pp. 210-228). De Gruyter Saur. 
Lindh, K., \& Haider, J. (2010). Development and the documentation of indigenous knowledge: Good intentions in bad company? Libri, 60(1), 1-14.

Lyons, R. (2012). Duck soup and library outcome evaluation. Public Library Quarterly, 31(4), 326-338.

Makri, S. (2020). Information informing design: Information science research with implications for the design of digital environments. Journal of Association for Information Science and Technology, 71, 1402-1412.

Mannheimer, S., Sterman, L. B., \& Borda, S. (2016). Discovery and reuse of open datasets: An exploratory study. Journal of eScience Librarianship, 5(1), e1091. https://doi.org/10.7191/ jeslib.2016.1091

Marett, A., Yunupingu, M., Langton, M., Gumbula, N., Barwick, L., \& Corn, A. (2006). The national recording project for indigenous performance in Australia: Year one in review. Retrieved from http://prijipati.library.usyd.edu.au/handle/ 2123/1337

Marsh, D. E., Punzalan, R. L., Leopold, R., Butler, B., \& Petrozzi, M. (2015). Stories of impact: The role of narrative in understanding the value and impact of digital collections. Archival Science, 16, 327-372.

Mato, P. J. (2009). Using a Digital Library as a Māori Language Learning Resource: Issues and Possibilities (Unpublished master's thesis). University of Waikato, Hamilton, New Zealand. Retrieved from http://researchcommons.waikato.ac.nz/handle/ $10289 / 3942$

Mercier, O. R., Douglas, S.-L., McFadgen, B., Hall, M., Adds, P., Bargh, M., \& Wilson, T. (2013). Promoting engagement through a student-built digital atlas of Maori studies. In Cutting-edge technologies in higher education (Vol. 6-F, pp. 121-158). Emerald Group.

Meyer, E. T. (2011). Splashes and ripples: Synthesizing the evidence on the impact of digital resources (Report). Joint Information Systems Committee (JISC). Retrieved from http://ssrn.com/ abstract $=1846535$

Misilei, J., \& Liew, C. L. (2018). Perceived value of digital components in library Programmes: The case of Auckland Libraries dare to explore summer reading programme. Library and Information Science Research, 40(3/4), 219-236.

Moss, M. (2017). Memory institutions, the archive and digital disruption? In A. Hoskins (Ed.), Digital memory studies: Media pasts in transition. Routledge.

Mutibwa, D. H. (2016). Memory, storytelling and the digital archive: Revitalising community and regional identities in the virtual age. International Journal of Media and Cultural Politics, 12(1), 7-26.

Nakata, N. M., Nakata, V. S., Anderson, J., Hunter, J., Hart, V., Smallacombe, S., McGill, J., Lloyd, B., Richmond, C., \& Maynard, G. (2007). Libraries and knowledge centres: Implementing public library services in remote indigenous communities in the Northern Territory of Australia. Australian Academic \& Research Libraries, 38(3), 216-231.

Poll, R. (2003). Measuring impact and outcome of libraries. Performance Measurement and Metrics, 4(1), 5-12.
Punzalan, R. L., Marsh, D. E., \& Cools, K. (2017). Beyond clicks, likes, and downloads: Identifying meaningful impacts for digitized ethnographic archives. Archivaria, 84, 61-102.

Reilly, M., \& Thompson, S. (2017). Reverse image lookup: Assessing digital library users and reuses. Journal of Web Librarianship, 11(1), 56-68.

Roy, L., \& Trace, C. (2018). Beyond stewardship and consultation: Use, care, and protection of indigenous cultural heritage. In C. L. Salvatore (Ed.), Cultural heritage care and management: Theory and practice. Rowman \& Littlefield.

Sheth, J. N., Newman, B. I., \& Gross, B. L. (1991). Why we buy what we buy: A theory of consumption values. Journal of Business Research, 22(2), 159-170.

Smith, J. A., Flowers, P., \& Larkin, M. (2009). Interpretative phenomenological analysis: Theory, method and research. Sage.

Spoonley, P., Peace, R., Butcher, A., \& O'Neill, D. (2005). Social cohesion: A policy and indicator framework for assessing immigrant and host outcomes. Social Policy Journal of New Zealand, 24(1), 85-110.

Stewart, G. (2019). He iti, he pounamu: The significance of doctoral theses written in te reo Māori. MAI Journal, 8(1), 77-90. https://doi.org/10.20507/MAIJournal.2019.8.1.6

Tanner, S. (2012). Measuring the impact of digital resources: The balanced value impact model. Retrieved from https://www.kdl.kcl. ac.uk/fileadmin/documents/pubs/ BalancedValueImpactModel_SimonTanner_October2012.pdf

Tanner, S. (2020). Delivering impact with digital resources. Facet Publishing.

Thompson, S., Kelly, E. J., Muglia, C., O'Gara, G., Stein, A., \& Woolcott, L. (2017). Developing a framework for measuring reuse of digital objects: A survey. Digital Library Federation Assessment Interest Group. Retrieved from https://osf.io/ ptvh5/

Tiakiwai, S.-J., Tiakiwai, H., \& Ministry of Education. (2010). A literature review focused on virtual learning environments (VLEs) and E-learning in the context of Te Reo Maori and Kaupapa Māori education (Report to the Ministry of Education. Retrieved from https://www.educationcounts.govt.nz/ publications/e-Learning/a-literature-review-focused-on-virtuallearning-environments/Section_3

UNESCO. (2003). Declaration concerning the intentional destruction of cultural heritage. Author. Retrieved from http://portal. unesco.org/en/ev.php-URL_ID $=17718 \& U R L \_D O=D O \_$ TOPIC\&URL_SECTION=201.html

Whaanga, H., Bainbridge, D., Anderson, M., Scrivener, K., Cader, P., Roa, T., \& Keegan, T. T. (2015). He Matapihi Ma Mua, Mo Muri: The ethics, processes, and procedures associated with the digitization of indigenous knowledge-The Pei Jones collection. Cataloging \& Classificaiton Quarterly, 53(5-6), 520-547.

Woolcott, L., Thompson, S., Kelly, E. J., Muglia, C., O'Gara, G., \& Stein, A. (2018). Use v. reuse: Assessing the value of our digital collections. Code4Lib. https://doi.org/10.17605/OSF.IO/ KE4B9 


\section{SUPPORTING INFORMATION}

Additional supporting information may be found online in the Supporting Information section at the end of this article.

How to cite this article: Liew, C. L., Yeates, J., \& Lilley, S. C. (2021). Digitized indigenous knowledge collections: Impact on cultural knowledge transmission, social connections, and cultural identity. Journal of the Association for Information Science and Technology, 1-18. https:// doi.org/10.1002/asi.24536

\section{APPENDIX A: GLOSSARY OF MĀORI TERMS}

ako (purposeful learning-teaching; learning outcome) hapu (subtribes; descent groups)

iwi (tribes)

kaitiaki (custodians)

kaitiakitanga (custodianship)

kanohi ki te kanohi (face-to-face communication) kapa haka (traditional Māori dancing and chanting) karanga (ritual chant of welcome) kaumātua (respected Māori elders) kaupapa (principles and values) kōrero (conversation/discussion/stories) kōruru (knucklebones; traditional Māori game) mana (spiritual life-force/social standing/prestige) manaakitanga (hospitality, care, mutual respect) marae (traditional Māori meeting house) mātauranga ā-iwi (tribal knowledge systems) mātauranga Māori (Māori knowledge systems) mauri (life-force) mihi (formal greeting)

mōteatea (song-poetry)

pepeha (epithet)

raweke (distort/manipulate)

tangata whenua ("people of the land"; group of people with historical claims to a district)

taonga (cultural property)

tapu (sacred)

tauutuututanga (reciprocity)

te ao Māori (Māori worldview)

te reo Māori (Māori language)

te reo rangatira (renewal/restoration of status, social standing of te reo)

tohungatanga (expertise in processing taonga and cultural knowledge)

tikanga (customary practices or principles)

tuakana-teina (reciprocal relationship between an older (tuakana) and a younger (teina) person; specific to teaching and learning in the Māori context)

tūpuna (grandparent or ancestor)

tūrangawaewae (sense of identity/independence associated with a particular home base)

waiata (song)

wairua (spirituality/soul)

wairuatanga (recognition of spiritual and restrictive nature of traditional knowledge)

wānanga (a publicly owned tertiary institution that provides education in the Māori context)

whakamana (legitimacy, empowerment, importance of knowledge to whānau, hapu, iwi)

whakapapa (genealogy)

whakawhanaungatanga (relationship building)

whaikōrero (formal speech-making)

whānau (extended families)

whanaungatanga (social relationships, social connections) whenua (land) 


\section{APPENDIX B: SUMMARY OF KEY FINDINGS}

T A B LE B 1 Summary of key findings according to value-impact frameworks and highlight of traditional cultural values

\author{
Value-impact focus and related value components from \\ value-impact frameworks reviewed (further details in \\ section 2.2.1) \\ Impact on knowledge gained; social connection, social prestige/ \\ respect; cultural identity; roles and responsibilities within \\ communities \\ Tanner $(2012,2020)$ - education; community \\ Sheth et al. (1991) - social; functional \\ Higgins and Rewi (2014) - social; cultural
}

Impact on learning, knowledge, heritage experience

Tanner $(2012,2020)$ - education

Sheth et al. (1991) - epistemic

Higgins and Rewi (2014) - educational; intellectual

Impact on knowledge access and transmission, social connection; heritage and cultural knowledge custodianship; cultural identity; emotional connections to ancestral, cultural heritage and community/collective identity; economic benefits

Tanner (2012, 2020) - utility; inheritance/legacy; existence/ prestige

Sheth et al. (1991) - emotional; conditional

Higgins and Rewi (2014) - intrinsic; spiritual; monetary

\section{Key findings of this study: Highlight of traditional cultural} values

- D-IKC link individuals and the social networks they interact with (Whanaungatanga) - recognition that traditional knowledge can make contributions to others (Tauutuututanga) and using knowledge to affirm cultural identity and ancestral relationships (Whakapapa)

- Access to D-IKC support and encourage purposeful learningteaching of the language and traditional knowledge-provides a sense of cultural satisfaction related to the value of lifelong learning (Ako) and cultural identity (Whakapapa)

- D-IKC contribute to raising awareness of resources/knowledge and individuals can be valuable "ambassadors"/trusted digital entry points (Ako, Whakamana)

- A degree of expertise in traditional knowledge (Tohungatanga) is required to ensure appropriate use and for the value of the resources to be truly realized

- The value of knowledge sharing and exchanges prompted by access and use of D-IKC is expressed through the cultural values of purposeful learning-teaching ( $A k o$ ), social connections (Whanaungatanga), empowering others through knowledge transfer and sharing (Whakamana) and reciprocal knowledge exchange (Tauutuututanga)

- Knowledge transfer and sharing facilitate relationship building among social networks (including with fellow students, academics and family members (Whakawhanaungatanga)

- Reciprocal knowledge exchange (Tauutuututanga) lead to restoration of the prestige/social standing of Māori language (Whakamana, Te Reo Rangatira) and provided a connection between self- and cultural identity to ancestral heritage (Whakapapa)

- The emotional and spiritual connections (Wairuatanga) gained through access and use of D-IKC are emphasized, along with acknowledgement that expertise in traditional knowledge (Tohungatanga) is required to ensure appropriate use and for the value of the resources to be truly realized

- Perceived value of D-IKC is affected by use of language (accuracy, correct dialects), connected to the prestige/social standing of the language (Te Reo Rangatira, Whakamana) and the ancestral knowledge contained within it (Whakapapa, Wairuatanga)

- The restrictive nature of certain traditional knowledge are necessary for integrity-protection (Wairuatanga) 